\title{
Study on Gender-related Speech Communication in Classical Chinese Poetry
}

\author{
Xinhe Tian ${ }^{1}$, Dandan Qin ${ }^{2}$ \\ ${ }^{1}$ Televsion School, Communication University of China, 1 Ding Fuzhuang East Stree, Chaoyang District, Beijing \\ 100024, China \\ ${ }^{2}$ Schoo of Foreign Language, Hubei University for Nationalities, 39 Xueyuan Road, Enshi, Hubei Province 445000, \\ China
}

Correspondence: Aijing He, 39 Xueyuan Road, Enshi, Hubei Province 445000, China.

Received: December 2, 2015

doi:10.11114/jets.v4i12.1985

\author{
Accepted: November 13, 2016 \\ Online Published: November 15, 2016 \\ URL: http://dx.doi.org/10.11114/jets.v4i12.1985
}

\begin{abstract}
:
Gender, formed in men and women's growth which is constrained by social context, is tightly tied to the distinction which is presented in the process of men and women's language use. Hence, it's a new breakthrough for studies on gender and difference by analyzing gender-related speech communication on the background of ancient Chinese culture.
\end{abstract}

Keywords: gender difference; speech communication; Classical Chinese poetry

\section{Introduction}

Male and Female languages refer to that which is usually used by men and women or that which is characteristic of gender differences.

For the past few years, people have accepted men and women's physiological and psychological characteristics and differences. But there are only a few researches about men and women's linguistic characteristics and differences. With respect to the genderlect difference, or sex dialect, studies on it begin in abroad. Until the 1960s to1970s, in the context of feminist campaign in the west, Lakoff published Language and Women's Place, then studies on genderlect difference started to be seen by linguists. From then, genderlect difference gradually became an important linguistic research.

Before the 1960s, people's researches about the gender language were scattered and extensive while systematic studies on it dated from then. English language was the main scope of the study and the content was focused on the men and women's pronunciation, vocabulary, sentence structure etc., such static aspects. Until the 1980s to 1990s, the research emphasis was turned to the dynamic aspects including the topic, response and others of gender speech communication under the different social background.

Under the influence of Europe and the United States, other countries came to attach importance to the study of the gender differences in language and the language they studied was beyond English to Chinese, Japanese, German etc. In our field of linguistics, paying more attention to the gender language is far more recently, however, linguists' focus is mainly confined to foreign languages. In contrast, the research about gender differences in Chinese language is relatively less. Further, studies on gender differences within the context of the Chinese language, especially in classical Chinese poetry are few.

Therefore, it's meaningful that the present article focuses on the classical Chinese poems to discuss the gender differences in it to add new blood to the subject. But before the article is set forth systematically, it must be pointed out that the classical Chinese poems selected below are translated by X. Y. Z (Xu Yuanchong), which can be accepted by most of researchers after being compared with other translated versions. So the problem of word selection due to different translators will not be discussed in the whole article.

The article uses classical Chinese poetry as an important entry point to state the gender differences in ancient literature. It can not only enrich the study of gender language, but also provide complement for such field by analyzing the classical Chinese poetry in English. It will make three transitions for the gender and language research, from the static state to the dynamic state, from macro to micro, from a simple discipline to a multidisciplinary study. In consequence, the research will bear important theoretical and realistic significance for studying the Chinese and gender problems. 
In a word, the aim of specifically analyzing the problem about gender and language is to explore relations between language and mankind so that we can recognize and learn the nature of language and its own internal rules of development.

\section{Literature Review}

\subsection{Definition and Comparison of Terms: Gender and Sex}

Before the comprehensive and systematic concept of gender and sex is defined, it's necessary to clarify the distinction between them first. According to Coulmas (2005), gender is culture while sex is nature. Specially, Shapiro states that gender differences are social and cultural impositions on biological distinction of sex (Holmes\& Meyerhoff, 2003). Holmes (2001), similarly, said, "gender is more appropriate for distinguishing people based on socio-cultural behavior, including speech, while sex refers to categories differentiated by biological characteristics." Likewise, Norton and Pavlenko (2004) define gender as a "complex system of social relations and discursive practices differentially constructed in local contexts."

Hence, gender is generally classified into a socio-cultural phenomenon, other than sex, which belongs to the scope of physical and psychological significance. In other words, gender has closer connection with the society than sex and has more obvious social nature, but gender is the term used to describe socially constructed categories based on sex.

\subsection{Gender and Language}

There is a long tie between gender and language. When talking with both genders, people tend to use different language, and their own gender differences also have an impact on language use. Therefore, the relationship between gender and language is often a two-way street. On one hand, gender causes the multiplicity of language. When the gender of speaker, the gender of audience and the gender of people who are mentioned are combined together, the language use will become different. So it can be said that human gender differences determine gender differences in language. On the other hand, language prompts gender distinctions and differences within the society, and fuels the pressure and distortion of patriarchal society to female personality in some degree. So language is part of micro-political structure and plays an important role in maintaining the political and economic structure of society.

\subsection{Study at Home and Abroad}

As mentioned in the Introduction, foreign scholars pay more attention to the gender differences in language. From a historical point of view, researchers find that studies on gender differences in language mainly can be divided into three stages: the early researches on gender differences in language, the modern gender researches and the postmodern gender construction. Up to today, the researches on gender differences in English have spread in phone, register, intonation, vocabulary, structure, grammar, meaning, discourse act, conversation mode, multi-language studies, verbal ability, language acquisition, the studies on universal law of language and literature. Apart from Lakoff (1975), Trudgill (1974), Zimmerman (1975), Destefano (1975), Bolinger (1980), Coates(1986) etc. all are representatives in this respect.

In our field of linguistics, linguists' focus is mainly confined to foreign languages. Our scholars engaged in this research include Dai Weidong (1983), Yang Yonglin (1989), Dai Qingxia (1993), Sun Jianru (1997), Xu Daming (2004) etc. They have published plenty of dissertations on this front. As far as its content is concerned, our domestic researchers have roughly divided such studies into four aspects: theory introduction and literature review, gender discrimination reflected in the language, gender language expression and gender differences in speech communication.

Thus it can be seen that researches on gender differences in language at home and abroad have achieved fruitful results in the language form as well as language use, which not only can provide a good theoretical basis for our understanding the gender differences in language use, but also can offer us a data-driven support to further study the gender differences. Even though the research on it has the infinite possible development space, the previous studies, after all, have experienced growth from nothing, insufficiency and imperfection to relative sufficiency and continued perfection, which lay a solid foundation for later research and further improvement. Therefore, researches in this area are undoubtedly of considerably realistic significance.

\section{Gender Differences in Classical Chinese Poetry}

\subsection{Linguistic Differences}

Gender differences in language can be reflected in multiple perspectives(such as phone, tone, intonation and structure etc.), while the article only discusses them through vocabulary, intonation and topic-related differences in a corpus of version of Chinese poetry.

\subsubsection{Vocabulary}

Due to the expressive differences when each gender shows the strength of feeling, they choose different vocabulary to 
express themselves. In general, women are accustomed to use exaggeration, euphemism and emphasizer etc that have strong emotional colors to strength the semantic effect as well as use more polite language. However, in contrast, men's language and vocabulary are wilder and they tend to use profanity and taboo words with challenge. As is known to linguistic scholars, the Classical Chinese poem is a special way for ancient writers s scholars and calligraphers to express their emotions, but in fact it's also a good kind of classical style to reflect the gender differences in language use.

Some versions of classical Chinese poetry translated by X.Y.Z(Xu Yuanchong) are listed below as examples to make a comparison.

\section{Tune: Phoenix Hairpin}

(Lu You) Pink hands so fine,

Gold-branded wine,

Spring paints the willows green palace walls can't confine.

East wind unfair,

Happy times rare.

In my heart sad thoughts throng;

We've severed for years long.

Wrong, wrong, wrong!

Spring is as green,

In vain she's lean,

Her kerchief soaked with tears and red with stains unclean.

Peach blossoms fall

Near deserted hall.

Our oath is still there, Lo!

No word to her can go.

No, no, no!

(Tang Wan) The world unfair,

True manhood rare.

Dusk melts away in rain and blooming trees turn bare.

Morning wind high,

Tear traces dry.

I'd write to you what's in my heart,

Leaning on rails, I speak apart.

Hard, hard, hard!

Go each our ways!

Gone are our days.

Like long, long ropes of swing my sick soul groans always.

The horn blows cold,

Night has grown old.

Afraid my grief may be descried,

I try to hide my tears undried.

Hide, hide, hide!

These two poems were written by Lu You and Tang Wan, a young couple who were compelled to divorce, to get emotional communication. From poems, it's not hard to find that the vocabulary the man uses is more objective and what he describes also tends to be objects. Such as "gold-branded wine" "palace walls" "willows" "wind" "hall" etc. All of these are expressed directly. While the woman expresses herself mainly by abstract things, such as "world" "manhood" "dusk" "soul" "night" etc. Even if some objects also are used to convey her feeling, like "rain" "blooming 
trees" "wind" "tear traces" etc., all seems like tenderness and indirection. Besides, the vocabulary the man uses is firm. forceful and powerful, such as "wrong, wrong, wrong!" "no, no, no!". While the woman shows her feeling softly and euphemistically, such as "hard, hard, hard!" "hide, hide, hide!".

It is well-known that poem is a special way to show one's feeling, which may be attributed to Chinese broad and profound vocabulary. Just as Li Bai's "How can I stoop and bow before the men in power, and so deny myself a happy hour!"'(Mount Skyland Ascended in a Dream ---a song of Farewell), he expresses himself very directly that he is unwilling to serve the power without hiding his true feeling by such simple words. His poem "A time will come to ride the wind and cleave the waves; I'll set my cloudlike sail to cross the sea which raves."(Hard is the Way of the World) also describes the situation straightforward by using objects("wind" "waves" "sail" "sea") to show his ambition boldly. As another example, "On war-torn land streams flow and mountains stand; in vernal town grass and weeds are o'ergrown." (Spring View) written by $\mathrm{Du} \mathrm{Fu}$ is a typical example to state that the man tends to use objective things("war-torn land" "streams" "mountains" "town" "grass" "weeds") to present the real scenes and convey his concern of the fate of his nation. His another poem "Try to ascend the mountain's crest; It dwarfs all peaks under our feet."(Gazing at Mount Tai) appears bold and heroic due to the specific and strong vocabulary. Caocao's "With crags high mountains rise; With water the sea's deep. With the help of the wise, an ordered world we'll keep." (A Short Song) also represents his ambition by describing the objects("crags" "mountains" "water" "sea" "the wise" "world") without any euphemism.

From the above, a simple conclusion can be arrived that the vocabulary men choose tends to be vivid and objective, which is direct and full of power.

However, the way that women show their emotions is different. Tang Wan, who is discussed above is one of examples. Besides, Li Qing zhao, as one of the most important representatives of the female poets in ancient China, is also a powerful example. For instance, her poem "Say not my soul is not consumed. Should western wind uproll the curtain of my bower, I would show a thinner face than yellow flower."(Tune: Tipsy in the Flowers' Shade) expresses her hardship of missing euphemistically by comparing herself with yellow flower. The vocabulary she uses is soft and mild("soul" "western wind" "curtain" "bower" "a thinner face" "yellow flower") by which she shows her feeling indirectly. Another famous poem written by her is "Such sorrow can by no means be driven away; From eyebrows kept apart, again it gnaws my heart."(Tune: A Twig of Mume Blossoms), which conveys women's sentimentality by using subtle and delicate words. As another example, "You'll be discarded to a lonely place, and with my lord you'll fall into disgrace" written by Lady Ban also shows that she has tendency to express her true feeling abstractly and indirectly. And the list goes on! Besides, the color words like "yellow" used in similar poems are another indication that women tend to perceive color words even stronger than men and that they feel the visible face of beauty deeper than men too. Such as "Dusk melts away in rain and blooming trees turn bare"(Tan Wan) "Fragrant pink lotus fade; autumn chills mat of jade."(Li Qingzhao, Tune: A Twig of Mume Blossoms).

Thus it can be seen that the vocabulary women use, says overall, is more inclined to soft and euphemistic words and emotional expression.

\subsubsection{Intonation}

Intonation refers to "the rise and fall of the pitch of the voice in speaking, especially as this affects the meaning of what is said". It is able to show various subtle feelings which can not be achieved by the words. It is generally believed that English is a kind of intonation language, while Chinese is a tone language as well as an intonation language. In Chinese, sentence intonation refers to the rise and fall of the pitch of the whole sentence, which is inside the range of suprasegmental components. It not only involves the sum of sound forms including speed, pitch and strength of a voice, but also includes stop, stress and height. Next, the intonation-related differences in the classical Chinese poetry will be analyzed in the following aspects.

\section{(i) The falling intonation}

According to many linguists, it is widely agreed that men's intonation pattern refers to more assertive and monotonous falling tone. When the classical Chinese poetry is appreciated, it's not hard to figure out that men's intonation, at least relatively speaking, sound like rather rough, bold and confident. In the same context, men's intonation is likely to be steady, decisive and full of rational characteristics. Hence, with regard to the falling\& rising intonation, men tend to use more falling intonation to indicate their firm attitude. Such as Xiang Yu's "I could pull mountains down, oh! With main and might." (Xiang Yu's last song) and Liu Bang's "A great wind rises, oh! The clouds are driven away." (Song of the Great Wind), all show men's straightforward manliness. From these, the bearing and power of men can be sensed and impress others. Meanwhile, men often tend to end with high falling tone in order to show their determination and decision, which reflects that they are in power for a long time and like to issue orders. For example, Cao Cao said in his poem like that "With the help of the wise, an ordered world we'll keep"(A Short Song). His strength can be felt by 
means of perceiving his intonation at the moment. Besides, even when men express their personal true emotions, they dare speak out bluntly and directly with a firm and powerful courage. Just like Lu You, when he suffers that his love with Tang Wan has no result, he directly and strongly expresses "In my heart sad thoughts throng; we've severed for years long. Wrong, wrong, wrong!" "Our oath is still there, Lo! No word to her can go. No, no, no!" (Tune: Phoenix Hairpin) full of resentment and pain with high falling tone, which embodies men's power and status very fully.

(ii) The rising intonation

Generally speaking, women's intonation pattern involves rising intonation, falling-rising intonation and inquisitive intonation.

However, it's difficult for us to analyze such aspects in detail by means of existing ancient poetry for women's attainments in this area are not much as well as their rising intonation is not shown obviously in poems. So women's intonation is just analyzed simply based on the existing corpus.

In contrast, women use more rising intonation in their real life, which reveals their tentativeness and uncertainty. But it is reflected relatively less in their poems. Rare examples can be come up with, such as Li Qing zhao's "Oh, what can $i$ do with a grief beyond belief!"(Tune: Slow, Slow, Song), her intonation is full of uncertainty with a slower pace but highlight her emotional color of frustration and helplessness.

However, in the majority of women's poems, the intonation of them shown in a written form seems smooth and steady without a big rise and fall, which shows their gentility, elegance and tenderness as well as sentimentality. From the artistic conception of the poems selected above, it can be seen that women tend to convey their feelings by soft, euphemistic and refined but unresolved tone, which reflects their characters of non confidence and indecision to some extent. Like Tang Wan, in the same context, she shows her love to Lu You by saying "I'd write to you what's in my heart, Leaning on rails, I speak apart. Hard, hard, hard! Afraid my grief may be described, I try to hide my tears undried. Hide, hide, hide!"'(Tune: Phoenix Hairpin). Taking context into consideration, we're not hard to find that the intonation she wants to show is deep and full of grief and what she expresses, similarly, is sadness and helplessness but she dares not express her resentment directly like Lu You, so her intonation is lack of strength.

Certainly, the study is just based on the classical Chinese poetry. In real life, women use more rising notes and often use them with interrogatory and consultation when they answer questions. Hence, Lakoff thought that the intonation talked above reflected women's psychological feature of hesitation and showing consideration for other people, which may be related to women's low social status then.

The speakers' emotions, characteristics and mentality can be known by their intonation for people's pains and joys can be expressed by their voice. So from the examples above, a conclusion can be inferred that the intonation of both genders really has difference. Men tend to use the falling intonation and speak out directly as well as say whatever they like, so their intonation, to some extent, is full of strength and determination. While women's rising intonation is likely to be tender, euphemistic and they often dare not speak out their true feelings directly due to much consideration.

Likewise, from the classical Chinese poetry selected above, it can be seen that men and women often talk different things. On the whole, the topic men love tends to be linked to the country or career. They pay more attention to their social life and dare reveal the social phenomena. In general, they can be divided into two levels: one is full of warm blood and a sense of patriotism, and is anxious for the national security; such as Liu Bang's "A great wind rises, oh! The clouds are driven away. I come to my native land, oh! Now the world is under my sway. Where can i find brave men, oh! To guard my four frontiers today!"(Song of the Great Wind), it shows his warm blood and ambitious goals clearly as well as rough and straightforward manhood. Du Fu's "But he died before he accomplished his career. How could heroes not wet their sleeves with tear on tear!" (Temple of the Premier of Shu) expresses his lofty respect to great performers. Similarly, Caocao's "With crags high mountains rise; With water the sea's deep. With the help of the wise, an ordered world we'll keep." (A Short Song) also shows grand aspirations of the hero of the time; the other tends to escape from the whirlpool of politics and its right and wrong due to the inflate official career and chooses to live a peace life as a nature lover and a hermit without saying anything. Just as Li Bai's "How can I stoop and bow before the men in power, and so deny myself a happy hour!" (Mount Skyland Ascended in a Dream---a song of Farewell), he is not involved with others but just follow his own heart and pursue true happiness. Tao Qian's "I weed at dawn though early still; I plod home with my moonlit hoe." (Return to NatureIII), similarly, shows his love to nature directly and his pleasure of enjoying the rural lifestyle .

Hence, it can be seen roughly that men's topic tends to be linked closely with their society reality and life with a bold and unconstrained, meaningful and natural as well as straightforward and broad-minded style.

In contrast, women tend to talk more about personal life, emotion, family and a bunch of little things, which is closely related to the condition of that time. In other words, they are inclined to stay out of politics and more cling to men. Lady 
Yu is a typical example. Her poem Reply to Xiang Yu, "With might and main my lord can't stand. Could a frail woman turn out strong!" expresses her deep love to Xiang Yu as well as a woman's strong emotional attachment to a man. Li Qingzhao's "Things are the same, but he's no more and all is o'er. Before I speak, how can my tears not pour!"(Tune: Spring in Peach-Blossom) also conveys the condition of personal life and her own strong emotions to the family and husband. Examples abound!

In other words, this often means that women's topic involves purely private life with a plain, ordinary, exquisite, implicit and euphemistic style due to their own limitations.

So, above all, there seems to have big differences in topic when men and women want to express themselves. In general, men and women see things from different angles. Men tend to look at things from the macroscopic view, while women are more inclined to see goods on a micro level. That's the reason why men like to talk about country, social phenomena, career and nature, while women like to talk about personal life and emotions. Besides, men focus on conveying information, while women aim at expressing personal feelings. However, it's necessary to add that men are glad to and keen to express themselves by means of words in written form, while women prefer to be listeners and readers and choose to hide their emotions or obscure their meanings. So when the classical Chinese poetry is looked through, it's not hard to find that men are more willing to create and write poems. Hence, from the number of poets and poems, men account for the major proportion. That's not just because men have more topics to choose, but also because the society then forms the latent pattern. Nevertheless it also shows, on the other hand, a difference of division, which reflects a fact that women remain in a very subordinate position in a patriarchal society.

\subsection{Causes of Gender Differences in Classical Chinese Poetry}

All of causes below are based on the background of the patriarchal society which is the foothold of the paper. There are many factors impacting on gender differences in language. The paper mainly discusses how the Chinese ancient social environment which is as an external factor, affects the gender and language in view of environment shaping personality.

\subsubsection{The Political Environment}

Ancient China has a so rigid feudal hierarchy that the patriarchal ideology has infiltrated into the country's political institutions. The idea that men are superior to women and the ideology of preference for sons are deep-rooted. Therefore, men are representatives of power and status. They are occupying the leading position due to be in power in the politics, which makes them full of superiority and forms them courageous and resolute characters and language features without fear. So just as Li Bai, poets like him, dare say “Heaven has made us talents, we're not made in vain."(Li Bai, Invitation to Wine). Their ambition and courage don't come inherently but are formed under the powerfully political environment. So they dare speak out directly and express themselves boldly without any hesitation by means of powerful words.

On the contrary, the subordination of women in the ancient times makes them rely on men from birth and stay out of politics. They need to be subject to men in a whole lifetime, obey the traditional doctrine, such as "obey her father before marriage, her husband when married, and her sons in widowhood" and lack of ego. Therefore, they dare not express themselves with reckless attitude. Instead, they have to be more cautious and careful as well as delicate and considerate. In this process, they form passive and dependent characters as well as soft and tender language features. So even if other female poets like Li Qingzhao, know the real social environment they live in, they can only say "I look for what I miss; I know not what it is. I feel so sad, so drear, so lonely, without cheer.”(Li Qingzhao, Tune: Slow, Slow, Song) unable to make any changes but bear the status quo. Hence, simply from the perspective of language use, there is no doubt that women are the weak under such political environment.

\subsubsection{The Economic Environment}

In ancient, men plowed the fields and women wove cloth, which is a summarization of gender roles in the traditional Chinese agriculture civilization. Nevertheless, men also have absolute predominance in feudal self-sufficient small-scale peasant economy and women's weaving cloth is just a supplement of individual farming. Because weaving cloth is a way of processing and the materials women need are still provided by men. It is known that the male parent is the owner of the means of production due to the private ownership of the feudal economy as well as the provider of raw materials and living materials. So based on the private property, the products made by women still belong to the male parent. Thus it can be seen that women attach themselves to men in economy and play a secondary role in life, which more or less contributes to gender differences in language use. This is also the real reason why Li Bai then had confidence to say “ A thousand gold coins spent, more will turn up again"(Invitation to Wine). In other words, men's predominance in the economy makes them full of superiority in language use.

While women's attached position in the economy, to some degree, makes them lose the right to speak. So when they are young, they need to listen to their fathers; when they get married, they have to follow their husbands; when they outlive their husbands, they must obey their sons. Hence, they are used to bearing men's orders and treading and speaking with 
caution. So compared with men, they suffer from a lack of wildness and directness. As time passes, they form their language features invisibly.

\subsubsection{The Cultural Environment}

Firstly, with the patriarchal culture spreading in the feudal country, women are in the subordinate position from birth. Another important fact is the education system in which men and women are not educated equally. Men are brought up with political thought and are given more attention by the nation and family. While women are taught more traditional moral ideas, such as "the three obediences and the four virtues", and their education is not valued by the family and government. Besides, values of men and women told by the society are also different. In general, men have a sense of mission from childhood while women regard "Innocence is the virtue for women" as a social judgment,etc. Hence, even if daughters of the royalty receive a good education, they still form a tender and delicate character (regardless of physiological factors) and remain in a subordinate position in such special culture surroundings, let alone female in normal families.

Therefore, we have to admit that the educational environments make men full of confidence and wildness in their bones from an early age. While women, on the contrary, form the character of weakness and shyness due to be unnoticed by the society. And their language also becomes gentle and polite for being influenced by the culture in which men have a dominant advantage. Besides, the education from birth makes them, both men and women, accept their different characteristics and take such distinction for granted. So men will keep their language features and regard them as a kind of right guidance, and women also insist on their special language styles. Hence, different educations and living environments have some effect on gender differences in language use.

\subsubsection{The Public Ideology}

Based on the analysis of several aspects above, it can be seen that the psychology of men and women living in the patriarchal society inevitably tends to be very different. As a whole, men have a strong sense of superiority while women have to obey men from cover to cover without resistance. The social environment makes women form an idea in their ideology that they are inferior, which is unshakable. Hence, women are willing to serve the men psychologically and take the men's high profile for granted. Naturally, they are pleased to play roles in supporting their husbands and educating their children in its essence as a second fiddle. While men are used to enjoying such superiority and domination throughout.

Therefore, in view of language use, men like to express themselves as an authority, straightforward and firmly. The superiority of their ideology forms them bold, generous and unconstraint personal characteristics and language features. While as men's status is higher than women's and the status of women is not steadier than men's, women more need to guarantee their social relationships in language and other ways. So they strive to speak civilly and regularly in the hope that their social position can be improved at some level. Hence, in their ideology, they form language features with quiet, timid, reserved, considerate, euphemistic but diffident characteristics.

In short, the social ideology forces people to modify their behavior according to their gender patterns. All behavior that fails to be consistent with social expectations and requirements will be objected and denied by society as well as be sneered at and despised by others. So gender differences in language come into being gradually.

\section{Conclusion}

The research about gender differences in language possesses quite significant sense in both theory and realism. After being groped for several decades, the research is from duality to multielement, from statics to dynamics, from macro to micro, from a large scale to the native. But it needs to be pointed out that the research on gender differences in language mostly tends to place western culture as its setting and use English as a main language. Hence, it's necessary to clutch the direction of research on international gender differences in language very well. And we also need to mine the relations between language and gender in different contexts, main-stream culture and non mainstream culture with multi-levels and multi-angles based on the native culture.

The thesis regards the classical Chinese poetry as a starting point to study gender differences in language in a specific cultural background and times. However, the existence of differences, to a large extent, is a negative reflection to the history and traditional culture, which shows that the eternal environment has a great impact on the formation of the gender differences in language.

In brief, the differences are not ascribed to the language itself but the products of gender physiological and psychological differences as well as closely related to the social environment and family culture. This goes to show the point that language, gender and society have a tight connection. Because individual is the body of language usage, the gender differences inevitably are reflected in language as a kind of social culture phenomenon, and change along with the development of society. By doing a study on gender differences in ancient poetry, analyzing its source, seeking the 
social state and nature, expressing the whole through details and making objective interpretation, we can find that language usage needs an equal and good social environment, which contributes to the further research on gender differences in language use.

\section{References}

Bagolinger, D. (1980). Language-The Loaded Weapon. London: Longman.

Coates, J. (1986). Women, Men and Language. London: Longman.

Coates, J. (1998). Language and gender: a reader. Oxford, Malden Mass: Blackwell.

Coulmas, F. (2005). Sociolinguistics: The study of speakers' choice. New York: Cambridge University Press. https:/doi.org/10.1017/CBO9780511815522

Dai, Q. X. (1993). An introduction to sociolinguistics. Beijing: Minzu University of China Press.

Dai, W. D. (1983). Review of gender difference in conversion. Journal of Foreign Language, 1983(6).

Destefano, J. (1975). Women's Language. Views on language, 1975(7).

Holmes, J. (2001). An introduction to sociolinguistics,2nd ed. New York: Longman.

Holmes, J., \& Meyerhoff, M. (2003). The handbook of language and gender [M]. Malden. MA: Blackwell. https:/doi.org/10.1002/9780470756942

Lakoff, R. (1975). Language and woman's Place. New York: Harper\&Row.

Norton, B., \& Pavlenko, A. (2004). Gender and English language learners. Alexandria, Va: TESOL.

Sun, J. R. (1997). Gender and Language. Nanjing: Jiangsu Education Press.

Sunderland, J. (2006). Language and gender: An advanced resource book. New York: Rutledge. https:/doi.org/10.4324/9780203456491

Trudgill, P. (1974). Sociolinguistics: An Introduction to Language and Society. London: Penguin Book, Harmondsworth.

Xu, Y. C. (2012). Book of Poetry. Beijing: Dolphin Books.

Y, Y. L. (1989). Gender feature in English syntax. Modern Foreign Language, 1989(9).

Zimmerman, D. H., \& Weats, C. (1975). Language and sex: Differences Dominance. Massachusetts: Rowley, Newbury House.

\section{$((c))$ EY}

This work is licensed under a Creative Commons Attribution 3.0 License. 